\title{
Central European plant species from more productive habitats are more invasive at a global scale
}

Petr Dostál ${ }^{1,2 *}$, Wayne Dawson ${ }^{2,3}$, Mark van Kleunen ${ }^{2,3}$, Lidewij H. Keser ${ }^{2}$ and Markus Fischer ${ }^{2}$

\author{
'Institute of Botany, Academy of Sciences of \\ the Czech Republic, CZ-252 43 Prühonice, \\ Czech Republic, ${ }^{2}$ Institute of Plant Sciences, \\ University of Bern, Altenbergrain 21, $\mathrm{CH}-3013$ \\ Bern, Switzerland, ${ }^{3}$ Ecology, Department \\ of Biology, University of Konstanz, \\ Universitätsstraße 10, D-78457 Konstanz, \\ Germany
}

\begin{abstract}
Aim Accumulating evidence indicates that species may be pre-adapted for invasion success in new ranges. In the light of increasing global nutrient accumulation, an important candidate pre-adaptation for invasiveness is the ability to grow in nutrient-rich habitats. Therefore we tested whether globally invasive species originating from Central Europe have come from more productive rather than less productive habitats. A further important candidate pre-adaptation for invasiveness is large niche width. Therefore, we also tested whether species able to grow across habitats with a wider range of productivity are more invasive.
\end{abstract}

Location Global with respect to invasiveness, and Central European with respect to origin of study species.

Methods We examined whether average habitat productivity and its width across habitats are significant predictors of the success of Central European species as aliens and as weeds elsewhere in the world based on data in the Global Compendium of Weeds. The two habitat productivity measures were derived from nutrient indicator values (after Ellenberg) of accompanying species present in vegetation records of the comprehensive Czech National Phytosociological Database. In the analyses, we accounted for phylogenetic relatedness among species and for size of the native distribution ranges.

Results Species from more productive habitats and with a wider native habitatproductivity niche in Central Europe have higher alien success elsewhere in the world. Weediness of species increased with mean habitat productivity. Niche width was also an important determinant of weediness for species with their main occurrence in nutrient-poor habitats, but not for those from nutrient-rich habitats.

Main conclusions Our results indicate that Central European plant species from productive habitats and those species from nutrient-poor habitat with wide productivity-niche are pre-adapted to become invasive. These results suggest that the world-wide invasion success of many Central European species is likely to have been promoted by the global increase of resource-rich habitats.

\section{Keywords}

Ellenberg nutrient indicator, environmental tolerance, Europe, human impact, introduced ranges, native ranges, plant invasiveness, resource availability.
Botany, Academy of Sciences of the Czech Republic, CZ-252 43 Průhonice, Czech Republic.

E-mail: dostal@ibot.cas.cz to play an important role (Pyšek \& Richardson, 2007; Schlaepfer et al,, 2010; Jenkins \& Keller, 2011). However, studies testing this by explicitly relating species attributes in their native range to invasiveness elsewhere are scarce (van

Kleunen et al., 2010).
A major question in ecology is what determines the invasiveness of exotic species. Among multiple explanatory mechanisms, pre-adaptation of introduced species has been suggested 
Most exotic species are introduced into highly populated areas (e.g. Chytrý et al., 2008), which are usually situated in regions of the world with fertile soils. Moreover, due to the dramatic increase in atmospheric nitrogen deposition (Galloway et al., 2004), and the increased use of fertilizers in agriculture in the last centuries, the global area of land with high nutrient availability has increased, and is likely to increase further (Vitousek et al., 1997). Therefore, we might expect that species originating from productive habitats in their native range are more likely to become invasive. Interestingly, although non-native species from resource-rich communities have been proposed to become successful invaders (Blumenthal et al., 2009; Hejda et al., 2009), an explicit test of the link between habitat productivity in the native range and invasiveness elsewhere is missing.

Similarly, species with wide niches, and thus most likely with high environmental tolerance, are expected to have a greater likelihood of encountering, and establishing in, suitable habitats when introduced to a new range. Therefore, we might also expect that species occurring under a wide range of habitat productivities in their native range are more likely to become invasive elsewhere. Previous studies have shown that the success of European plant species in non-European regions is associated with environmental, presumably climatic, tolerance in the region of origin (Prinzing et al., 2002; Pyšek et al., 2009). Similarly, Alexander et al. (2011) found that non-native species with broad climatic tolerances are more successful along altitudinal gradients than species adapted to specific elevations. However, to the best of our knowledge, it has not been tested whether species capable of growing in habitats of a wide range of productivities are more likely to become invasive than species occurring in habitats of a narrow range of productivities.

In this study, we tested the relationship between global success of Central European plant species and their median and niche width of habitat productivity in the native range. Because the importance of species attributes for invasion success may differ between growth forms and habitat types (Tecco et al., 2010), we restricted our study to the most common ones, i.e. non-woody species occurring in terrestrial and littoral habitats. Moreover, to ensure that we really consider species native to Europe, we used species known to occur in Europe prior to Neolithic activity, i.e. we excluded archaeophytes and neophytes (Pyšek et al., 2002).

As a proxy for habitat productivity, we used indicator values for nutrient levels after Ellenberg et al. (1992) based on accompanying species in vegetation records of a very comprehensive national vegetation database (the Czech National Phytosociological Database; Chytrý \& Rafajová, 2003). We used numbers of non-European references and of world regions in the Global Compendium of Weeds (GCW; Randall, 2002) to estimate alien success of European species elsewhere in the world. Because not all GCW references refer explicitly to invasive or weedy species, we also quantified 'weediness' of the species using only the references that explicitly list invasive and weedy species (see also Pyšek et al., 2009).

In this context, it needs to be considered that species occurring in productive habitats and occurring across a wide range of habitats of different productivity are also more common in their native range. Therefore, such species might have had a greater likelihood of being introduced elsewhere due to both a longer introduction history and higher propagule pressure (Colautti et al., 2006; Pyšek \& Richardson, 2007). In our analyses we accounted for such potential introduction bias by considering distributional characteristics in the native range as covariates. Moreover, as different species may not yield independent data points due to a shared evolutionary history, we corrected for phylogenetic relatedness among species (Felsenstein, 1985; Freckleton et al., 2002; Cadotte et al., 2006).

\section{METHODS}

\section{Success elsewhere and productivity of native habitats}

To assess the global success of Central European species, we used the number of non-European references per species listed in the GCW (Randall, 2002). This is currently the most exhaustive such compilation, based on almost 300 reference lists of alien plants (including weedy and invasive ones) from around the world, and it has been used in several previous studies involving regional or global invasiveness (Pyšek et al., 2009; Dawson et al., 2011; Jenkins \& Keller, 2011). It should be noted that there are several limitations of the GCW (Richardson \& Rejmánek, 2004). Some of the reference lists included in the GCW are rather vague with regard to the invasiveness status of the listed species, and some regions of the world are overrepresented. Furthermore, some reference lists are incomplete or include species that are considered to have invasive potential but have not yet become invasive. Despite these flaws, which can be partly accounted for, the GCW is the most comprehensive source on global invasiveness of plant species that is currently available.

As we mentioned above, categorization of exotic species in some reference lists regarding their invasion status is not clear or is rather vague compared with criteria defined by, for example, Richardson et al. (2000). Therefore, we used an approach similar that of Pyšek et al. (2009). First, for 264 Central European species, we compiled information on what we call 'alien success'. It was expressed as the number of non-European references listing our 264 study species (there were 159 references at maximum) without precise definition of their status. It thus may include Central European species in non-European locations at various invasion stages spanning from casual up to invasive taxa (sensu Richardson et al., 2000). Second, we compiled information on what we call 'weediness'. It is expressed as the number of non-European references that explicitly defined the invasion status of species listed as weed, quarantine weed, noxious weed, environmental weed or invasive alien. However, we did not consider those references listing only weeds of cultivated land such as crop weeds and weeds of parks or of lawns as references to 'weediness'. Because such habitats receive high amounts of additional fertilizer, inclusion of these references might otherwise have resulted in upward-biased estimates of weediness for species occurring in productive anthropogenic habitats. We 
ended up with 109 reference lists at maximum that were selected from the 159 lists used for alien success. We conducted analyses of weediness with 196 species (with at least one GCW reference) that were a subset of species used in the analysis of alien success. Species included in the weediness analyses can be considered to have a more precisely defined status and are associated with later stages of the invasion process.

Despite its global coverage, the GCW is biased towards certain regions. Of the $159 \mathrm{GCW}$ references included for the analysis of alien success, most references $(44.7 \%)$ come from North America (Canada and the USA), whereas other global regions, such as Africa (reference share of $6.9 \%$ ), are less well represented. Unequal frequencies of recipient continents, and thus of recipient environments, might influence the results of this study. Therefore, for each species (in both the analysis of alien success and that of weediness), we also used the number of nonEuropean global regions represented by at least one GCWW reference as a more conservative measure of alien success or weediness (Dawson et al., 2011). The 10 global regions were North America, South America, Central America, Africa, Pacific, Australasia, Middle East, South Asia, East Asia and Southeast Asia.

We estimated habitat productivity and niche width in this parameter for each of the selected species in the native range by using 20,468 vegetation records selected from 65,730 records (number of records in July 2004) of the Czech National Phytosociological Database (hereafter CNPD; Chytrý \& Rafajová, 2003). Record selection was done by stratified resampling of the database to reduce the effect of oversampling with respect to habitat type in some areas (Chytrý et al., 2005). To ensure that our habitat-productivity estimates are representative for the study species, we only selected species that were present in at least 200 vegetation records in a subset of the CNPD.

For each species, we randomly picked 100 vegetation records of the CNPD subset. For each of these records, we calculated mean indicator values for nutrients after Ellenberg $(N)$ based on accompanying species with the program rurce (Tichý, 2002). Per vegetation record, $\mathrm{N}$-values were available on average for $72.3 \%( \pm 0.3 \% \mathrm{SE})$ of the accompanying species. The system of Ellenberg indicator values for several environmental characteristics has been developed for approximately 3000 vascular plant species occurring in the western part of Central Europe, and indicator values for mutrients were supposed to reflect the availability of nitrogen (Ellenberg et al., 1992). Diekmann (2003) in his review documented that mean $N$ calculated from species present at a site can be poorly related to the total amount of nitrogen or total nitrogen mineralization rate at the site. However, it nevertheless reflects well the amount of ammonium or nitrate ions and other macronutrients $(P, K)$ in the soil. It is also correlated with the standing crop and nitrogen accumulation in plants (Diekmann, 2003). So, the $N$ indicator value covers a broad range of macronutrients.

Finally, for each species, we calculated the median and interquartile range of the 100 mean $\mathrm{N}$-values derived from the vegetation records. We used the median as estimate of habitat productivity instead of the mean because the median is not sensitive to skewed distributions and outliers. Inter-quartile range (difference between the third and the first quartiles) was employed as an estimate of niche width with respect to $N$-values rather than the range from minimum to maximum, because it is less sensitive to outliers.

Wamelink et al. (2002) demonstrated that the relationship between mean Ellenberg indicator values derived from vegetation and environmental parameters measured directly in the field can be influenced by the identity of the phytosociological class. This means that even if two species from different vegetation types have similar environmental requirements, mean $N$ based on the vegetation can falsely indicate environmental differentiation between them. Such an error can be expected for species that are specialists in terms of vegetation types, and thus occur in few phytosociological classes. This was unlikely to be the case in our study, because the 100 vegetation records selected for the calculation of $N$-values of each species came on average from 23.55 ( $\pm 0.14 \mathrm{SE}$ ) phytosociological classes (minimum = 17 classes). Moreover, the most frequent phytosociological classes were the same for species with very distinct median $N$ (see Appendix S1 in Supporting Information).

Jansen et al. (2011) indicated another possible problem with the calculation of $N$. They argued that, because of non-random species co-occurrence patterns in vegetation records, significant differences in mean $N$ between groups of vegetation records can be found even if indicator values are randomly assigned to species in the records. We tested this idea, and we found that random assignment of indicator values to accompanying species in our data set resulted in non-significant differences in mean $N$ between study species (Appendix S1). Therefore, we conclude that the potential problem indicated by Jansen et al. (2011) does not apply to our dataset.

There were large differences in the number of vegetation records available for different species in the CNPD subset (range 1-4592). As mentioned above, we therefore included only species well represented in the CNPD subset by at least 200 records, and used 100 records as sample size for our calculations. The number of records in which a species occurred was not associated with its median $N\left(F_{1,262}=2.50, P=0.12\right)$, but tended to be positively associated with the inter-quartile range of $N$ $\left(F_{1,262}=3.52, P=0.06\right)$. We also checked for possible confounding effects of differences in the mean plot size of vegetation records (mean $\pm \mathrm{SE}=59.03 \pm 0.59 \mathrm{~m}^{2}$ ) used for different species. However, it affected neither the median of $N\left(F_{1,262}=\right.$ $0.003, P=0.95)$ nor its inter-quartile range $\left(F_{1,262}=0.84, P=\right.$ 0.36 ) among the 264 species.

Species that are common in their native range are also more likely to be picked up and introduced elsewhere. To be able to correct for such a possible introduction bias, we also compiled distributional data at two different spatial scales in the native range. First, at a larger scale, we obtained the number out of 34 European countries in which the species is native from the online database Flora Europaea (http://rbg-web2.rbge.org.uk/ $\mathrm{FE} / \mathrm{fe}$.html). Second, at a finer scale we obtained species frequency from species geographical distributions in the Czech Republic from the FLDOK database (J. Štěpánek and J. Wild, 
Institute of Botany ASCR, the Czech Republic, personal communication). FLDOK provides the presence or absence of species in the Czech flora in each of 2551 cells, each measuring $5^{\prime}$ longitude by $3^{\prime}$ latitude (c. $33.3 \mathrm{~km}^{2}$ ). We assessed species frequency as the number of occupied grid cells out of 2551 . Species frequencies at both spatial scales were positively correlated with each other $(R=0.276$, d.f. $=262, P<0.001)$, indicating that species that are abundant in the Czech Republic are also widespread across Europe.

\section{Statistical analyses}

We used generalized least squares regression (GLS) in the nlme package (Pinheiro et al., 2011) of R version 2.11.0 (R Development Core Team, 2010) to test whether alien success and weediness were related to the median and inter-quartile range of $N$. Median $N$ was significantly positively related to the number of European countries in which species were native and to their frequency in the Czech Republic (see Appendix S2), which in turn might be related to time of introduction and propagule pressure in the introduced range (Colautti et al., 2006; Pyšek \& Richardson, 2007). Therefore, we also ran the models with either the Czech Republic or Europe-wide distributional range data as a covariate. In addition, we ran the model including the number of available CNPD vegetation records per species as a covariate because it could have influenced the calculation of the interquartile range of $N$ (see above).

We entered a phylogenetic correlation structure into a phylogenetic generalized least squares regression model (PGLS) using the ape package in R (Paradis et al., 2004). PGLS models are identical to the method of independent contrasts developed by Felsenstein (1985) and require the same phylogenetic information as that needed for computing independent contrasts. Rather than constructing contrasts, however, PGLS involves regression with expected variances of and correlations between error terms based on the available phylogenetic topology and branch lengths (Garland \& Ives, 2000). We used a Pagel (1999) phylogenetic correlation structure, which is derived from the Brownian-motion model by multiplying the off-diagonal elements of the phylogenetic variance-covariance matrix by $\lambda$ $(0 \leq \lambda \leq 1)$. A value of $\lambda=0$ indicates emergence of traits that are independent of phylogeny and $\lambda=1$ indicates that traits are evolving according to Brownian motion on the given phylogeny (Pagel, 1999; Freckleton et al., 2002).

We constructed the phylogeny of our species using the online tool Phylomatic (Webb \& Donoghue, 2005). The topology of the tree generated by Phylomatic was based on an expert interpretation of the APG III (Angiosperm Phylogeny Group, 2009) phylogenetic classification of flowering plant orders and families. Within-family phylogenetic relationships were resolved using published molecular phylogenies (see Appendix S3).

Branch lengths were adjusted using the bladj function in PHYLocom version 4.1 (Webb et al, 2008). This function fixes the root node at a specified age, and fixes other nodes with available age estimates. It then calibrates all other branch lengths by placing the nodes evenly between dated nodes, and between dated nodes and branch tips (Webb et al., 2008). For the calibration, we used the aged angiosperm nodes from Wikström et al. (2001).

We then compared respective models using the Akaike information criterion (AIC), with a lower value indicating a better model fit to the data. Models with phylogenetic structure always yielded significantly lower AIC values, with the significance of predictors unchanged. We therefore only report results of the models with phylogeny included.

For all regressions, we angularly transformed proportions of the number of non-European GCW references (out of 159 for alien success or 109 for weediness) or GCW regions (out of 10 for both alien success and weediness) to achieve a normal distribution of residuals. We also angularly transformed the proportion of European countries in which the species is native and the proportion of occupied grid cells in the Czech Republic. Explanatory variables were standardized to zero mean and unit variance to facilitate comparisons of effect size estimates (Schielzeth, 2010).

\section{RESULTS}

\section{Alien success}

Both median $N$ and the inter-quartile range of $N$ of species were positively related to the number of GCW references and the number of GCW regions (Table 1, Fig. 1). Relationships of median $N$ and its inter-quartile range with alien success also remained significant after distributional range data in the native range and the number of available records in the CNPD database were included in the models (Table 1). This clearly indicates that species from more productive habitats and with a wider native habitat-productivity niche in Central Europe are more likely to establish elsewhere in the world.

\section{Weediness}

Median $N$ was consistently positively related to weediness in terms of number of GCW references across all models (Table 1, Fig. 2a). The main effect of inter-quartile range of $N$ on weediness was significantly positive according to the model with the lowest AIC value (which included the number of European countries as a covariate; Table 1, Fig. 2 c). In the other analyses, inter-quartile range of $N$ had a positive effect on weediness of species with low median $N$, while it had no or even a weakly negative effect on weediness of species with higher median $N$ (Appendix S4). This was reflected in significant median $\times$ interquartile range interactions for weediness in terms of GCW references (Table 1). Weediness in terms of GCW regions was significantly positively influenced only by median $N$ and not by inter-quartile range of $N$ (Table 1, Fig. 2b, d).

\section{DISCUSSION}

In this study, we showed that Central European species associated with more productive habitats are more successful (in 
ळ Table 1 Coefficient estimates and $t$-values obtained from phylogenetic generalized least squares (PGLS) analyses exploring the relationship of median nutrient indicator value $N$ of plant species at their origin and the inter-quartile range (IR) of $N$ with alien success (a) and weediness (b) elsewhere. Both alien success and weediness were expressed as number of references and number of regions in the Global Compendium of Weeds (GCW; Randall, 2002) (see Methods). Distributional characteristics in the native range were used as covariates by including the number of European countries in which the species is native, or by including their frequency in the Czech Republic. The number of vegetation records with the respective species in a subset of the Czech National Phytosociological Database (CNPD; Chytrý \& Rafajová, 2003) was also used as covariate. Two hundred and sixty-four species were included in the analyses of alien success and 196 species in the analyses of weediness. Significant effects (at $P<0.05$ ) are in bold. Akaike information criterion (AIC) values are provided for each model.

\begin{tabular}{|c|c|c|c|c|c|c|c|c|}
\hline \multirow[b]{2}{*}{ GCW references } & \multicolumn{2}{|l|}{$\begin{array}{l}\text { No covariate } \\
\text { AIC }=-312.4\end{array}$} & \multicolumn{2}{|l|}{$\begin{array}{l}\text { Number of EU countries } \\
\text { AIC }=-407.3\end{array}$} & \multicolumn{2}{|c|}{$\begin{array}{l}\text { Frequency in the Czech Republic } \\
\mathrm{AIC}=-310.8\end{array}$} & \multicolumn{2}{|c|}{$\begin{array}{l}\text { Number of records in CNPD } \\
A \mathrm{AC}=-336.0\end{array}$} \\
\hline & Coefficient estimate (SE) & $t$-value & Coefficient estimate (SE) & $t$-value & Coefficient estimate (SE) & $t$-value & Coefficient estimate (SE) & $t$-value \\
\hline $\begin{array}{l}\text { Native range distribution size } \\
\text { Median } N \\
\text { IR } \\
\text { Median } \times \text { IR }\end{array}$ & $\begin{array}{r}0.036(0.008) \\
0.028(0.007) \\
-0.010(0.008)\end{array}$ & $\begin{aligned} & 4.4^{* * *} \\
& 3.6^{* * *} \\
&-1.3 \text { n.s. }\end{aligned}$ & $\begin{array}{r}0.077(0.007) \\
0.021(0.007) \\
0.024(0.007) \\
-0.001(0.007)\end{array}$ & $\begin{array}{l}11.4^{* * *} \\
3.2^{* * *} \\
3.7^{* *} \\
-0.2 \text { n.s. }\end{array}$ & $\begin{array}{r}0.024(0.008) \\
0.031(0.008) \\
0.026(0.008) \\
-0.009(0.008)\end{array}$ & $\begin{array}{c}2.9^{* * *} \\
3.6^{* * *} \\
3.3^{* *} \\
-1.2 \text { n.s. }\end{array}$ & $\begin{array}{r}0.044(0.007) \\
0.033(0.008) \\
0.022(0.008) \\
-0.011(0.007)\end{array}$ & $\begin{array}{c}6.0^{* * * *} \\
4.3^{* * *} \\
3.0^{* *} \\
-1.5 \mathrm{n} . \mathrm{s.}\end{array}$ \\
\hline $\begin{array}{l}\text { Median } \times \text { IR } \\
\text { Men }\end{array}$ & \multicolumn{2}{|l|}{$\begin{array}{l}\text { No covariate } \\
\mathrm{AIC}=-153.8\end{array}$} & \multicolumn{2}{|l|}{$\begin{array}{l}\text { Number of EU countries } \\
\mathrm{AIC}=-222.6\end{array}$} & \multicolumn{2}{|c|}{$\begin{array}{l}\text { Frequency in the Crech Republic } \\
\text { AIC }=-145.9\end{array}$} & \multicolumn{2}{|c|}{$\begin{array}{l}\text { Nurnber of records in CNPD } \\
A C=-171.9\end{array}$} \\
\hline GCW regions & Coefficient estimate (SE) & t-value & Coefficient estimate (SE) & $t$-value & Coefficient estimate (SE) & itvalue & Coefficient estimate (SE) & itvalue \\
\hline $\begin{array}{l}\text { Native range distribution size } \\
\text { Median } N \\
\text { IR } \\
\text { Median } \times \text { IR }\end{array}$ & $\begin{aligned} 0.052(0.011) \\
0.040(0.011) \\
-0.008(0.011)\end{aligned}$ & $\begin{aligned} 4.6^{* * *} \\
3.7^{* * *} \\
-0.7 \text { n.s. }\end{aligned}$ & $\begin{array}{l}0.091(0.010) \\
0.035(0.010) \\
0.034(0.009) \\
0.002(0.009)\end{array}$ & $\begin{array}{l}9.6^{* * *} \\
3.6^{* * *} \\
3.6^{* * *} \\
0.2 \mathrm{n} . \mathrm{s}\end{array}$ & $\begin{array}{r}0.012(0.011) \\
0.049(0.011) \\
0.038(0.011) \\
-0.007(0.011)\end{array}$ & $\begin{array}{r}1.1 \text { n.s. } \\
4.3^{* * *} \\
3.6^{\star * *} \\
-0.7 \text { n.s. }\end{array}$ & $\begin{array}{r}0.053(0.010) \\
0.048(0.01) \\
0.032(0.010) \\
-0.010(0.010)\end{array}$ & $\begin{array}{r}5.4^{* * *} \\
4.5^{* * *} \\
3.1^{* *} \\
-1.0 \mathrm{n.s.}\end{array}$ \\
\hline \multicolumn{9}{|l|}{ (b) Weediness } \\
\hline & \multicolumn{2}{|l|}{$\begin{array}{l}\text { No covariate } \\
\text { AIC }=-227.8\end{array}$} & \multicolumn{2}{|l|}{$\begin{array}{l}\text { Number of EU countries } \\
\text { AIC }=-267.4\end{array}$} & \multicolumn{2}{|c|}{$\begin{array}{l}\text { Frequency in the Czech Republic } \\
\text { AIC }=-221.5\end{array}$} & \multicolumn{2}{|c|}{$\begin{array}{l}\text { Number of records in CNPD } \\
A C=-230.4\end{array}$} \\
\hline GCW references & Coetficient estimate (SE) & $t$-value & Coefficient estimate $(S E)$ & $t$-value & Coefficient estimate (SE) & $t$-value & Coefficient estimate (SE) & $t$-value \\
\hline $\begin{array}{l}\text { Native range distribution size } \\
\text { Median } N \\
\text { IR } \\
\text { Median } \times \text { IR }\end{array}$ & $\begin{array}{r}0.028(0.008) \\
0.010(0.009) \\
-0.023(0.008)\end{array}$ & $\begin{array}{l}3.1^{* *} \\
1.1 \mathrm{n} . \mathrm{s} . \\
-2.9^{* *}\end{array}$ & $\begin{array}{r}0.074(0.009) \\
0.023(0.009) \\
0.017(0.008) \\
-0.004(0.008)\end{array}$ & $\begin{array}{l}8.2^{* * *} \\
2.7^{* *} \\
2.1^{*} \\
-0.4 \text { n.s. }\end{array}$ & $\begin{array}{r}0.024(0.009) \\
0.028(0.009) \\
0.009(0.009) \\
-0.020(0.008)\end{array}$ & $\begin{array}{c}2.6^{* *} \\
3.0^{* *} \\
1.0 \mathrm{n} . \mathrm{s.} \\
-2.3^{*}\end{array}$ & $\begin{array}{r}0.040(0.009) \\
0.030(0.009) \\
0.009(0.009) \\
-0.020(0.008)\end{array}$ & $\begin{array}{l}4.1^{* * * *} \\
3.2^{* *} \\
1.1 \mathrm{I} . .5 \\
-2.4^{*}\end{array}$ \\
\hline Median $\times$ IR & \multicolumn{2}{|l|}{$\begin{array}{l}\text { No covariate } \\
\text { AIC }=-133.0\end{array}$} & \multicolumn{2}{|l|}{$\begin{array}{l}\text { Number of EU countries } \\
\text { AIC }=-198.5\end{array}$} & \multicolumn{2}{|c|}{$\begin{array}{l}\text { Frequency in the Czech Repubtic } \\
\mathrm{AIC}=-125.3\end{array}$} & \multicolumn{2}{|c|}{$\begin{array}{l}\text { Number of records in CNPD } \\
\mathrm{AIC}=-137.7\end{array}$} \\
\hline GCW regions & Coefficient estimate ( $\mathrm{SE}$ ) & $t$-value & Coefficient estimate (SE) & $t$-value & Coefficient estimate (SE) & $t$-value & Coefficient estimate (SE) & t-value \\
\hline $\begin{array}{l}\text { Native range distribution size } \\
\text { Median } N \\
\text { IR } \\
\text { Median } \times \mathbb{I R}\end{array}$ & $\begin{array}{r}\mathbf{0 . 0 4 6}(0.013) \\
0.004(0.012) \\
-0.022(0.011)\end{array}$ & $\begin{array}{c}3.7^{* * *} \\
0.3 \mathrm{n} . . . \\
-1.8\left(^{* *}\right)\end{array}$ & $\begin{array}{r}0.102(0.011) \\
0.023(0.010) \\
0.005(0.010) \\
-0.009(0.010)\end{array}$ & $\begin{array}{l}9.6^{* * *} \\
3.0^{* * *} \\
0.5 \text { n.s. } \\
-0.9 \text { n.s. }\end{array}$ & $\begin{array}{r}0.014(0.012) \\
0.042(0.013) \\
0.002(0.012) \\
-0.022(0.011)\end{array}$ & $\begin{array}{r}1.1 \mathrm{nts.s.} \\
3.3{ }^{* \star} \\
1.2 \mathrm{ns.s.} \\
-1.9\left(^{* *}\right.\end{array}$ & $\begin{array}{r}0.048(0.013) \\
0.044(0.012) \\
0.001(0.012) \\
-0.022(0.012)\end{array}$ & $\begin{array}{l}3.7^{* * *} \\
3.6 * * * \\
0.1 \text { n.s. } \\
-2.0\left(0^{*}\right)\end{array}$ \\
\hline
\end{tabular}

$* * * P<0.001 ; * * P<0.01 ; * P<0.05 ;{ }^{*} 0.05<P<0.10 ;$ n.s., not significant. 
(a)

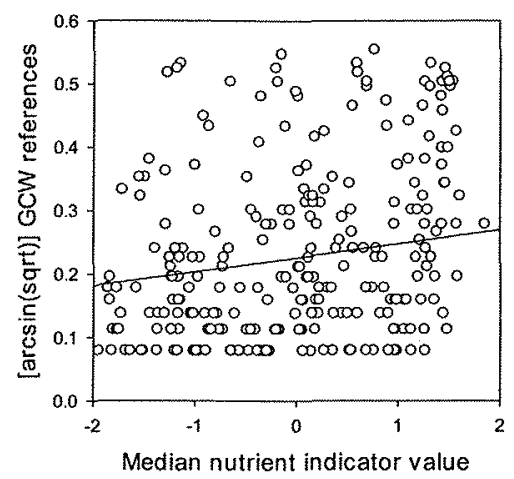

gure 1 Relationship of alien success with median nutrient indicator value $N$ (a,b) and inter-quartile range of $N(\mathrm{c}, \mathrm{d})$ of 264 Central European species. Alien success was expressed as number of references $(a, c)$ and number of regions (b, d) in the Global Compendium of Weeds (GCW). See Methods for the transformation of variables. Note that for illustration phylogenetically uncorrected raw data points are depicted. Linear best fits come from phylogenetic generalized least squares regression models with both productivity parameters and frequency in Europe as covariate and considering phylogenetic structure.

Figure 2 Relationship of weediness with median nutrient indicator value $N(a, b)$ and the inter-quartile range of $N(c, d)$ of 196 Central European species. Weediness was expressed as number of references $(a, c)$ and number of regions $(b, d)$ in the Global Compendium of Weeds (GCW). Note that for illustration phylogenetically uncorrected raw data points are depicted. Linear best fits come from phylogenetic generalized least squares regression models with both productivity parameters and frequency in Europe as covariate and considering phylogenetic structure. The inter-quartile range of $N$ had no significant effect on the number of regions (d). (c)

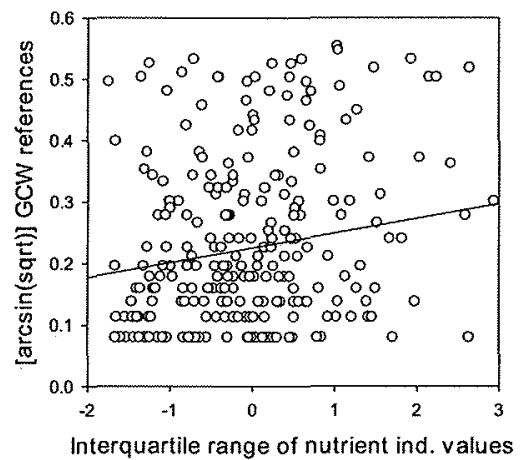

(a)

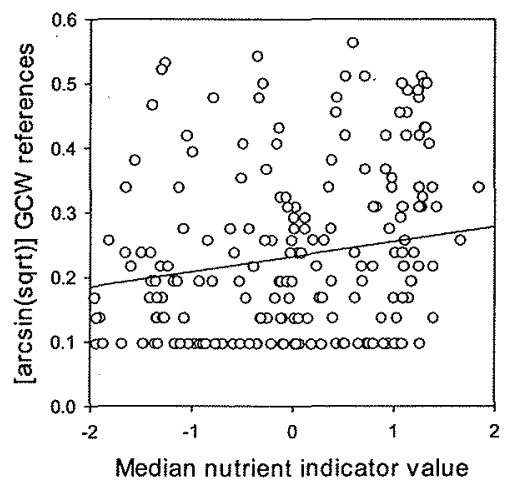

(c)

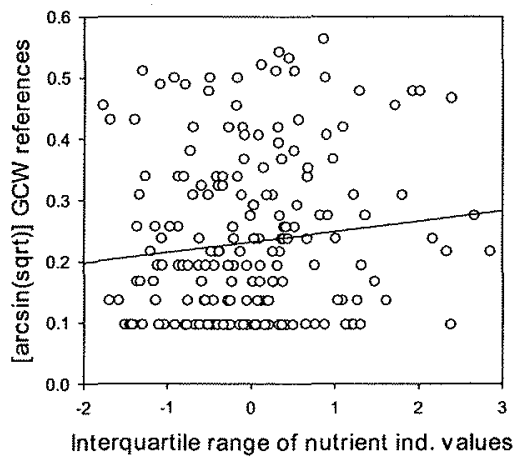

(b)

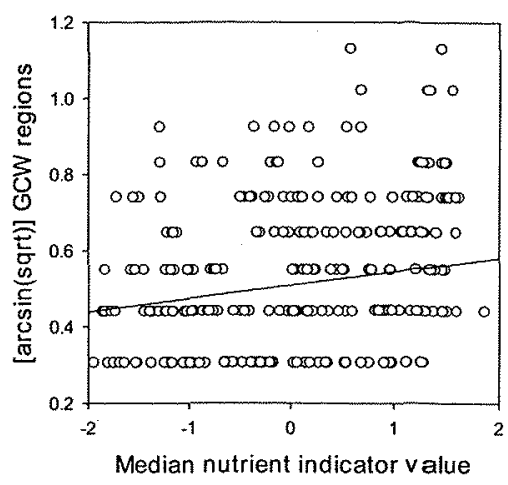

(d)

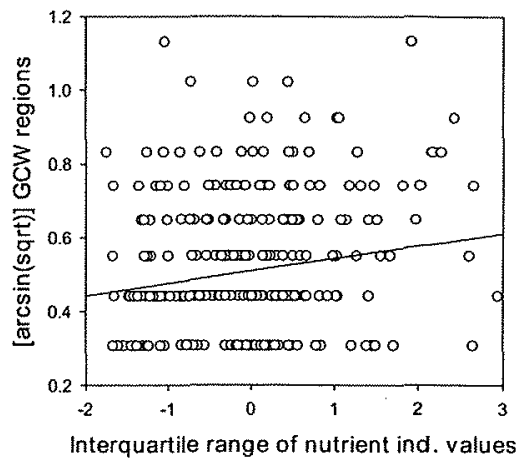

(b)

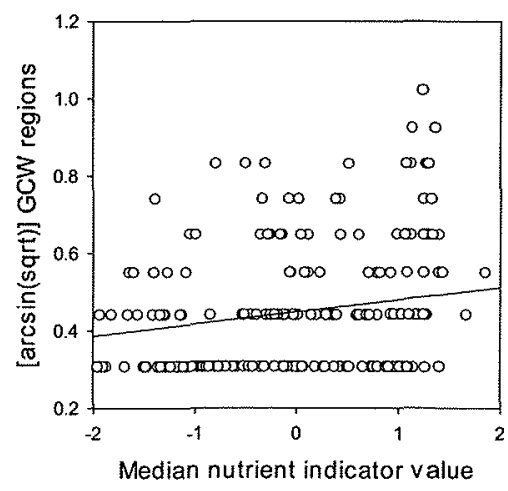

(d)

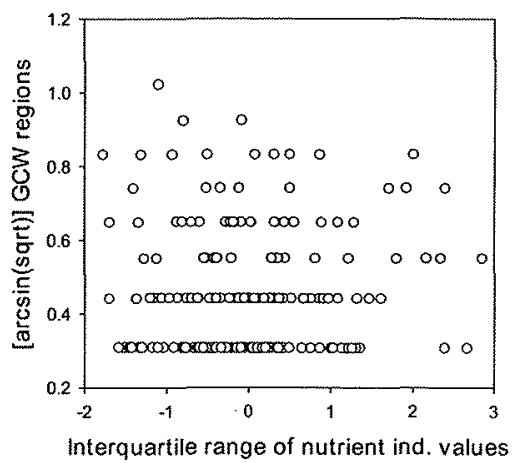


terms of both alien success and weediness) in other parts of the world than species originating from more resource-poor habitats. It is likely that species from productive habitats succeeded in other parts of the world because they possess traits enabling them to exploit human-dominated landscapes characterized by nutrient enrichment and disturbance. Traits typically associated with invasive species are fast growth rate, large specific leaf area and production of small and numerous seeds (Rejmánek \& Richardson, 1996; Pyšek \& Richardson, 2007; van Kleunen et al., 2010; Dawson et al., 2011). These traits are also frequently associated with species from productive habitats (Grime, 1979). Indeed, for 74 species that overlapped with species used in a study by Dawson et al. (2011), which revealed a positive association between maximum relative growth rate and global invasiveness, we found that median $N$ was positively correlated with maximum growth rate $(r=0.374$, d.f. $=72, P<0.001)$. So, overall our results are in line with the idea that those species that possess traits allowing them to take advantage of high resource levels are more likely to become invasive.

Alien success of species also increased with their capacity to occupy habitats of a wider range of productivities. This supports the niche-width hypothesis (sensu Brown, 1984), which predicts that species able to use a wider range of habitats also tend to be more widespread. Previous studies concerned with niche characteristics other than productivity also found support for a positive relationship between niche width and size of introduced ranges (Prinzing et al., 2002; Pyšek et al., 2009; Alexander $e t$ al., 2011). However, some of these previous studies used rather coarse estimates of niche width such as the number of floristic zones or the number of habitat types in which species are occurring. Pyšek et al. (2009) argued that the number of floristic zones in which a species occurs stands primarily for species climatic tolerance. Also, however, it may indicate tolerance of species to other factors, such as variation in geological substrate. Our study is novel by explicitly linking the native habitatproductivity niche width among species with their success elsewhere. Together with climatic tolerance, the ability to grow in a wide range of productivities is probably the most important determinant of native species distribution as suggested from nutrient addition experiments (e.g. Suding et al., 2005). Our study adds that it is an indicator of alien success in introduced ranges as well.

Our results indicate that niche width promotes weediness of species that have their main occurrence in nutrient poor habitats in their native range. Species of highly productive habitats become weedy in new ranges irrespective of whether they are also able to occupy more or less fertile sites. The capacity to grow in a wider range of habitats is often attributed to increased adaptive phenotypic plasticity (Bradshaw, 1965; Richards et al., 2006). Richards et al. (2006) thus assume that invasive species are more plastic than non-invasive species. For species included in this study, we did not determine experimentally whether more successful species are those with increased phenotypic plasticity in resource use. Funk (2008) demonstrated that species invasive in Hawaii exhibited greater plasticity in several leaf- and plant-level traits than native relatives in response to nutrient availability. Davidson et al. (2011) showed in a recent meta-analysis that invasive species were nearly always more plastic (in their response to greater resource availability) than native species were. Further recent studies showed that invasive alien species outperform non-invasive alien species under several different environmental conditions, but did not find higher invasiveness associated with higher plasticity in morphological traits (Schlaepfer et al., 2010). Overall, while most studies indicate that more invasive species have a higher environmental tolerance it is not clear whether this is generally due to high plasticity.

Alternatively, the capacity to grow in a wider range of habitats could be accounted for by higher genetic variability, possibly evolved in response to such environmental heterogeneity. The latter would be expected theoretically (e.g. Via \& Lande, 1987), and was found in evolutionary experiments in the laboratory (Mackay, 1981). On the other hand genetic diversity may be impoverished in the introduced range compared with the native range due to founder effects (Husband \& Barrett, 1991). Consequently, even if high genetic variability explains the ability to grow in several different niches in the native range, this ability may be lost after colonizing a new range.

Habitat productivity in the native range was not only positively related to alien success and weediness of species elsewhere, but also to the number of European countries in which species were present and to their abundance (grid-cell occupancy) in the Czech Republic (Appendix S2). In Europe, this relationship is probably due to the current dominance of productive habitats, which is further being enhanced by human impact (Vitousek et al., 1997). In the Czech Republic, productive habitats such as most forests, grasslands and arable fields cover $c .81 \%$ of the territory (Storch et al., 2003). Much less productive habitats such as rocky habitats (scree slopes) or heathlands only cover $0.01 \%$ and $0.05 \%$ of the Czech land area, respectively.

To conclude, our study, which accounted for phylogenetic non-independence and for distributional characteristics in the native range, showed that significant variation in plant invasion success is accounted for by differences in their affinity to the productivity of habitats in their native range. To some extent, the ability to grow in a wide range of habitat productivities is also important. These findings support the view that many successfully invasive species may be pre-adapted for invasiveness (van Kleunen et al., 2010; Jenkins \& Keller, 2011). Moreover, our results suggest that the world-wide invasion success of many Central European species is likely to have been promoted by the global increase of resource-rich habitats. Therefore, the next step should be to explore whether the species from productive habitats are indeed successful because they established in similar habitats elsewhere, i.e. in resource-rich environments, and perform well in such conditions.

\section{ACKNOWLEDGEMENTS}

This study was supported by GACR grant no. P504/10/0132 and partly by GA ASCR grant no. AV0Z60050516, and was completed when P.D. was a Sciex-NMS ${ }^{\text {ch }}$ fellow (Project Code 
09.056). Milan Chytrý and Dana Michalcová, administrators of the Czech National Phytosociological Database, are acknowledged for providing vegetation records. Further thanks are due to Jan Štěpánek and Jan Wild who provided us the data from FLDOK database. M.F. and M.vK. acknowledge grants of the NCCR Plant Survival and of the Sino-Swiss Science and Technology Cooperation.

\section{REFERENCES}

Alexander, J.M., Kueffer, C., Daehler, C.C., Edward, P.J., Pauchard, A., Seipel, T. \& MIREN Consortium (2011) Assembly of nonnative floras along elevational gradients explained by directional ecological filtering. Proceedings of the National Academy of Sciences USA, 108, 656-661.

Angiosperm Phylogeny Group (2009) An update of the Angiosperm Phylogeny Group classification for the orders and families of flowering plants: APG III. Botanical Journal of the Linnean Society, 161, 105-121.

Blumenthal, D., Mitchell, C.E., Pyšek, P. \& Jaroł̌ík, V. (2009) Synergy between pathogen release and resource availability in plant invasion. Proceedings of the National Academy of Sciences USA, 106, 7899-7904.

Bradshaw, A.D. (1965) Evolutionary significance of phenotypic plasticity in plants. Advances in Genetics, 13, 115-155.

Brown, J.H. (1984) On the relationship between abundance and distribution of species. The American Naturalist, 124, 255279.

Cadotte, M.W., Murray, B.R. \& Lovett-Doust, J. (2006) Ecological patterns and biological invasions: using regional species inventories in macroecology. Biological Invasions, 8, 809-821.

Chytrý, M. \& Rafajová, M. (2003) Czech National Phytosociological Database: basic statistics of the available vegetationplot data. Preslia, 75, 1-15.

Chytrý, M., Pyšek, P., Tichý, L., Knollová, I. \& Danihelka, I. (2005) Invasions by alien plants in the Czech Republic: a quantitative assessment across habitats. Preslia, 77, 339-354.

Chytrý, M., Maskell, L.C., Pino, J., Pyšek, P., Vilà, M., Font, X. \& Smart, S.M. (2008) Habitat invasions by alien plants: a quantitative comparison among Mediterranean, subcontinental and oceanic regions of Europe. Journal of Applied Ecology, 45, $448-458$.

Colautti, R.I., Grigorovich, I.A. \& MacIsaac, H.J. (2006) Propagule pressure: a null model for biological invasions. Biological Invasions, 8, 1023-1037.

Davidson, A.M., Jennions, M. \& Nicotra, A.B. (2011) Do invasive species show higher phenotypic plasticity than native species and, if so, is it adaptive? A meta-analysis. Ecology Letters, 14, 419-431.

Dawson, W., Fischer, M. \& van Kleunen, M. (2011) The maximum relative growth rate of common UK plant species is positively associated with their global invasiveness. Global Ecology and Biogeography, 20, 299-306.

Diekmann, M. (2003) Species indicator values as an important tool in applied plant ecology - a review. Basic and Applied Ecology, 4, 493--506.
Ellenberg, H., Weber, H.E., Düll, R., Wirth, W., Werner, W. \& Paulißen, D. (1992) Zeigerwerte von Pflanzen in Mitteleuropa, Ed. 2. Scripta Geobotanica, 18, 1-258.

Felsenstein, J. (1985) Phylogenies and the comparative method. The American Naturalist, 125, 1-15.

Freckleton, R.P., Harvey, P.H. \& Pagel, M. (2002) Phylogenetic analysis and comparative data: a test and review of evidence. The American Naturalist, 160, 712-726.

Funk, J.L. (2008) Differences in plasticity between invasive and native plants from a low resource environment. Journal of Ecology, 96, 1162-1173.

Galloway, J.N., Dentener, F.J., Capone, D.G., Boyer, E.W., Howarth, R.W., Seitzinger, S.P., Asner, G.P., Cleveland, C.C., Green, P.A., Holland, E.A., Karl, D.M., Michaels, A.F, Porter, J.H., Townsend, A.R. \& Vörösmarty, C.J. (2004) Nitrogen cycles: past, present, and future. Biogeochemistry, 70, 153-226. Garland, T., Jr \& Ives, A.R. (2000) Using the past to predict the present: confidence intervals for regression equations in phylogenetic comparative methods. The American Naturalist, 155, 346-364.

Grime, J.P. (1979) Plant strategies and vegetation processes. John Wiley and Sons, Chichester.

Hejda, M., Pyšek, P., Pergl, J., Sádlo, J., Chytrý, M. \& Jarošík, V. (2009) Invasion success of alien plants: do habitat affinities in the native distribution range matter? Global Ecology and Biogeography, 18, 372-382.

Husband, B.C. \& Barrett, S.C.H. (1991) Colonization history and population genetic structure of Eichhornia paniculata in Jamaica. Heredity, 66, 287-296.

Jansen, J., Ewald, J. \& Zerbe, S. (2011) Ecological preferences of alien plant species in north-eastern Germany. Biological Inva sions, 13, 2691-2701.

Jenkins, C. \& Keller, S.R. (2011) A phylogenetic comparative study of preadaptation for invasiveness in the genus Silene (Caryophyllaceae). Biological Invasions, 13, 1471-1486. van Kleunen, M., Weber, E. \& Fischer, M. (2010) A metaanalysis of trait differences between invasive and non-invasive plant species. Ecology Letters, 13, 235-245.

Mackay, T.F.C. (1981) Genetic variation in varying environments. Genetical Research, 37, 79-93.

Pagel, M. (1999) Inferring the historical patterns of biological evolution. Nature, 401, 877-884.

Paradis, E., Claude, J. \& Strimmer, K. (2004) APE: analyses of phylogenetics and evolution in R language. Bioinformatics, 20, 289-290.

Pinheiro, J., Bates, D., DebRoy, S., Sarkar, D. \& Development, R. (2011) nlme: linear and nonlinear mixed effects models. $\mathrm{R}$ package version 3-1-98. Available at: http://www.r-project. org/

Prinzing, A., Durka, W., Klotz, S. \& Brandl, R. (2002) Which species become aliens? Evolutionary Ecology Research, 4, 385405.

Pyšek, P. \& Richardson, D.M. (2007) Traits associated with invasiveness in alien plants: where do we stand? Biological invasions (ed. by W. Nentwig), pp. 97-125. Springer, New York. 
Pyšek, P., Sádlo, J. \& Mandák, B. (2002) Catalogue of alien plants of the Czech Republic. Preslia, 74, 97-186.

Pyšek, P., Jarošík, V., Pergl, J., Randall, R., Chytrý, M., Kühn, I., Tichý, L., Danihelka, J., Chrtek jun, J. \& Sádlo, J. (2009) The global invasion success of Central European plants is related to distribution characteristics in their native range and species traits. Diversity and Distributions, 15, 891-903.

R Development Core Team (2010) $R$ : a language and environment for statistical computing. R Foundation for Statistical Computing, Vienna.

Randall, R. (2002) A global compendium of weeds. R.G. and F.J. Richardson, Meredith, Vic.

Rejmánek, M. \& Richardson, D.M. (1996) What attributes make some plant species more invasive? Ecology, 77, 16551661.

Richards, C.L., Bossdorf, O., Muth, N.Z., Gurevitch, J. \& Pigliucci, M. (2006) Jack of all trades, master of some? On the role of phenotypic plasticity in plant invasions. Ecology Letters, 9, 981-993.

Richardson, D.M. \& Rejmánek, M. (2004) Conifers as invasive aliens: a global survey and predictive framework. Diversity and Distributions, 10, 321-331.

Richardson, D.M., Pyšek, P., Rejmánek, M., Barbour, M.G., Panetta, F.D. \& West, F.D. (2000) Naturalization and invasion of alien plants: concepts and definitions. Diversity and Distributions, 6, 93-107.

Schielzeth, H. (2010) Simple means to improve the interpretability of regression coefficients. Methods in Ecology and Evolution, 1, 103-113.

Schlaepfer, D.R., Glättli, M., Fischer, M. \& van Kleunen, M. (2010) A multi-species experiment in their native range indicates pre-adaptation of invasive alien plant species. New Phytologist, 185, 1087-1099.

Storch, D., Konvička, M., Beneš, J., Martinková, J. \& Gaston, K.J. (2003) Distribution patterns in butterflies and birds of the Czech Republic: separating effects of habitat and geographical position. Journal of Biogeography, 30, 1195-1205.

Suding, K.N., Collins, S.L., Gough, L., Clark, C., Cleland, E.E., Gross, K.L., Milchunas, D.G. \& Pennings, S. (2005) Functional- and abundance-based mechanisms explain diversity loss due to $\mathrm{N}$ fertilization. Proceedings of the National Academy of Sciences USA, 102, 4387-4392.

Tecco, P.A., Díaz, S., Cabido, M. \& Urcelay, C. (2010) Functional traits of alien plants across contrasting climatic and land-use regimes: do aliens join the locals or try harder than them? Journal of Ecology, 98, 17-27.

Tichý, L. (2002) JUICE, software for vegetation classification. Journal of Vegetation Science, 13, 451-453.

Via, S. \& Lande, R. (1987) Evolution of genetic variability in a spatially heterogenous environment: effects of genotypeenvironment interaction. Genetical Research, 49, 147-156.
Vitousek, P.M., Mooney, H.A., Lubchenko, J. \& Melillo, J.M. (1997) Human domination of Earth's ecosystems. Science, 277, 494-499.

Wamelink, G.W.W., Joosten, V., van Dobben, H.F. \& Berendse, F. (2002) Validity of Ellenberg indicator values judged from physico-chemical field measurements. Journal of Vegetation Science, 13, 269-278.

Webb, C.O. \& Donoghue, M.J. (2005) Phylomatic: tree assembly for applied phylogenetics. Molecular Ecology Notes, 5, 181183.

Webb, C.O., Ackerly, D.D. \& Kembel, S.W. (2008) Phylocom: software for the analysis of phylogenetic community structure and trait evolution. Bioinformatics, 24, 2098-2100.

Wikström, N., Savolainen, V. \& Chase, M.W. (2001) Evolution of the angiosperms: calibrating the family tree. Proceedings of the Royal Society B: Biological Sciences, 268, 2211-2220.

\section{SUPPORTING INFORMATION}

Additional Supporting Information may be found in the online version of this article:

Appendix S1 An overview of species used in this study and limitations in calculating productivity parameters

Appendix S2 Results of generalized least squares analyses exploring the relationship between habitat productivity parameters and distributional characteristics in the native range Appendix S3 References used to resolve within-family phylogenetic relationships

Appendix S4 Effect of the interaction of nutrient parameters on weediness

As a service to our authors and readers, this journal provides supporting information supplied by the authors. Such materials are peer-reviewed and may be re-organized for online delivery, but are not copy-edited or typeset. Technical support issues arising from supporting information (other than missing files) should be addressed to the authors.

\section{BIOSKETCH}

Petr Dostál is a post-doctoral plant ecologist. His research focuses on the ecology of biotic interactions and their importance in plant invasions.

Editor: Brad Murray 